\title{
DYNAMIC PROGRAMMING APPROACH TO PENSION FUNDING: THE CASE OF INCOMPLETE STATE INFORMATION
}

BY

\author{
S. Haberman and Joo-Ho Sung
}

\begin{abstract}
Haberman and Sung (1994) have presented a dynamic model for a defined benefit occupational pension scheme which considered two types of risk: the "contribution rate" and the "solvency" risk. The current paper extends this work by deriving optimal funding control procedures for determining the contribution rate for the case of a stochastic model with incomplete state information, making use of the separation principle. The stochastic inputs modelled are the investment returns and the benefit outgo.
\end{abstract}

\section{KEYWORDS}

Pension funding, dynamic programming, stochastic control, separation principle.

\section{INTRODUCTION}

Haberman and Sung (1994) have presented a stochastic dynamic funding model for a defined benefit pension scheme under the circumstances that (i) there is no accounting bias and lags in actuarial valuations (i.e. the complete state information case), (ii) there is random disturbances only for investment rate of return and (iii) the fund level is a controlled variable, the contribution rate is a controlling variable and the control performance is designed to give a discounted weighted penalty to the deviations from their targets.

The motivations for extending our former work are as follows.

Firstly, the valuation process may not be able to refer to the exact financial status of the scheme at the valuation date, largely due to the physical inaccessibility of some of the economic parameters, inaccuracies in the measurement procedures and the costs of determining the exact values of the important state variables. Thus, this paper treats the incomplete state information case: the effects of delays in the valuation process have also been analysed by Haberman (1992, 1993), and Zimbidis and Haberman (1993). Given that the financial status of the pension scheme would be reviewed at 
the next valuation date, we believe that it is reasonable to focus on a one-unit time delay in the financial accounts. Secondly, stochastic demographic disturbances are of potential importance and so we incorporate both stochastic demographic and economic disturbances in the model rather than consider only stochastic economic disturbances. Thirdly, actuaries (including supervisory authorities) have an increasing interest in controlling the current and future scheme's solvency ratios. In this respect, the fund ratio is controlled instead of the fund level and the contribution ratio is controlled instead of the contribution rate, so that the control performance is designed to give a (not discounted) weighted penalty to the deviations from their target ratios. The use of ratios in this context has been proposed by Chang (1999).

The purpose of this paper is to derive the optimal pension funding plan for determining contribution ratios and the consequential optimal fund ratios (subject to given constraints) in the case of a stochastic model with incomplete state information, which has been constructed according to the above motivations. The extensions to longer accounting lags than one time unit would follow in a straightforward manner.

\section{Model Construction and Assumptions}

As with any model, it is necessary to make a number of simplifying assumptions in order that we may focus effectively on the key features of the problem to be solved. Adapting the optimal stochastic control theory for the incomplete state information case to pension funding, we construct a mathematical model with the following elements (i) (iv). Here, we work with a finite control period $(0, T)$, in which $\mathrm{T}$ is a positive integer.

\section{(i) Stochastic Controlled Dynamics}

We assume that valuations are carried out periodically so that, at time $t \in Z$ $(\equiv\{0,1,2, \ldots \mathrm{T}-1\})$, an actuarial valuation is conducted in order to estimate the

$\mathrm{AL}_{\mathrm{t}}$ : the actuarial liability at time $\mathrm{t}$, in respect of all members at time $\mathrm{t}$.

$F_{t}$ : the size of the scheme funds at time $t$, measured in terms of the market value of the underlying assets.

$C_{t}$ : the contribution to apply to $(t, t+1)$, which we assume, for convenience to be payable at time $t$.

We assume that the benefit outgo in year $(t, t+1)$ occurs immediately after time $t$ and we denote the actual outgo by $B_{t}$ and the outgo assumed in the valuation by $\mathrm{EB}_{\mathrm{t}}$. We let $\mathrm{NC}_{\mathrm{t}}$ be the normal cost at time $\mathrm{t}$ : this would be the contribution level if all of the actuarial assumptions were realised exactly.

We work with a simplified pension scheme where the only benefit offered is a final salary benefit. We assume that there is a single age at entry (a) and a single age of retirement ( $r$ ). It is assumed that the number of new entrants 
and the level of salaries grow geometrically and that this has applied for a sufficiently long period of time so that a demographically stable population results (in the sense of Keyfitz (1985)).

Then, the following recurrence relations hold:

$F_{t+1}=\exp \left(\delta_{t+1}\right)\left(F_{t}+C_{t}-B_{t}\right)$

$\mathrm{AL}_{\mathrm{t}+1}=\exp (\eta)\left(\mathrm{AL}_{\mathrm{t}}+\mathrm{NC}_{\mathrm{t}}-\mathrm{EB}_{\mathrm{t}}\right)$

$A L_{t+1}=\exp (\alpha+\beta) A L_{t}$

where $\delta_{t+1}$ is the force of interest corresponding to the rate of investment return, defined in a manner consistent with $F_{t}$, during the period $(t, t+1)$ and is assumed to be constant over $(t, t+1) ; \eta$ is the force of interest corresponding to the valuation interest rate, assumed to be constant for all $t$; $\alpha$ is the force of membership growth and $\beta$ is the force of salary growth.

Then, from (1) and (3), we obtain

$\mathrm{FR}_{\mathrm{t}+1}=\exp \left(\varphi_{\mathrm{t}+1}\right)\left(\mathrm{FR}_{\mathrm{t}}+\mathrm{CR}_{\mathrm{t}}-\mathrm{BR}_{\mathrm{t}}\right)$

where we define the funding ratio, $\mathrm{FR}_{t}=\frac{F_{t}}{\mathrm{AL}_{\mathrm{t}}}$, contribution ratio, $\mathrm{CR}_{t}=\frac{\mathrm{C}_{\mathrm{t}}}{\mathrm{AL}_{\mathrm{t}}}$, benefit ratio, $\mathrm{BR}_{\mathrm{t}}=\frac{\mathrm{B}_{\mathrm{t}}}{\mathrm{AL}_{\mathrm{t}}}$ and $\varphi_{\mathrm{t}+1}=\delta_{\mathrm{t}+1}-\alpha-\beta$.

Here, we introduce two stochastic processes, $\left\{\delta_{t+1} ; t \in Z\right\}$ and $\left\{B_{t} ; t \in Z\right\}$, as defined below, in order to incorporate the real world phenomena of random economic and demographic disturbances into the dynamics of the funding ratio dynamics, given by (4). For each unit period $(t, t+1)$, we assume that

$\delta_{\mathrm{t}+1}=\eta+{ }^{\mathrm{a}} \varepsilon_{\mathrm{t}+1}$ and $\mathrm{B}_{\mathrm{t}}=\mathrm{EB}_{\mathrm{t}}+{ }^{\mathrm{b}} \varepsilon_{\mathrm{t}+1}$

where

${ }^{\mathrm{a}} \varepsilon_{\mathrm{t}+1}$ is a random variable which follows an independent and identically distributed $\mathrm{N}\left(0, \sigma_{\mathrm{a}}^{2}\right)$ distribution (with $\left.\sigma_{\mathrm{a}}^{2}<\infty\right)$ and similarly ${ }^{\mathrm{b}} \varepsilon_{\mathrm{t}+1} \sim$ iid $\mathrm{N}\left(0, \sigma_{\mathrm{b}}^{2}\right)$, (with $\sigma_{b}^{\mathrm{a}}<\infty$ ) and ${ }^{\mathrm{a}} \varepsilon_{\mathrm{i}+1}$ and ${ }^{\mathrm{b}} \varepsilon_{\mathrm{j}+1}$ are mutually independent for all $\mathrm{i}, \mathrm{j} \in \mathrm{Z}$.

Thus, from (5), we derive the following linear stochastic dynamic model as a stochastic version of (4), which governs the behaviour of the variable to be controlled: for all $\mathrm{t} \in \mathrm{Z}$,

$\mathrm{FR}_{\mathrm{t}+1}=\exp \left(\varphi_{\mathrm{t}+1}\right)\left(\mathrm{FR}_{\mathrm{t}}+\mathrm{CR}_{\mathrm{t}}-\mathrm{BR}_{\mathrm{t}}\right)$

where

$\varphi_{t+1}=(\eta-\alpha-\beta)+{ }^{\mathrm{a}} \varepsilon_{\mathrm{t}+1} \equiv \mu+\varepsilon_{\mathrm{t}+1} \sim$ iid $\mathrm{N}\left(\mu, \sigma_{\mathrm{a}}^{2}\right)$; and

$\mathrm{BR}_{\mathrm{t}}=\frac{\mathrm{EB}_{\mathrm{t}}}{\mathrm{AL} \mathrm{L}_{\mathrm{t}}}+\frac{{ }^{\mathrm{b}} \varepsilon_{\mathrm{t}+1}}{\mathrm{AL} \mathrm{L}_{\mathrm{t}}} \sim$ iid $\mathrm{N}\left(\mathrm{EBR}_{\mathrm{t}}, \mathrm{VBR}_{\mathrm{t}}\right)$, where $\mathrm{VBR}_{\mathrm{t}}=\frac{\sigma_{\mathrm{b}}^{2}}{\mathrm{AL}_{\mathrm{t}}^{2}}$. 


\section{(ii) Actuarial Valuation Process}

Unlike the complete state information case, we introduce an observable/realisable valuation variable $\mathbf{M}_{t}$ (i.e. which is the output from the actuary's valuation process) for dealing with the incomplete state information case, so that we can formulate the characteristics of including accounting lags in the actuarial valuation. Thus, for all $t \in Z$, we define

$M_{t}=F_{t-b}$ with the given initial condition $M_{0}=F R_{-b}$

where $b$ denotes the accounting lag parameter and $b \in\{1,2,3, \ldots\}$.

As mentioned in section 1 , we only consider here the case of " $b=1$ " on the grounds that, in practice, a one-unit time delay would be the most likely case. Thus, the pension scheme actuary, at time $t$ does not have direct access to the current value of $F_{t}$; for this reason, $F_{t}$ is called the conceptual state variable. Then, he is required to estimate $F_{t}$ from the information available up to time $t$, represented by the information vector at time $t \equiv \mathfrak{I}_{\mathrm{t}}=\left(\mathrm{FR}_{-1}, \mathrm{FR}_{0}\right.$, $\left.\ldots, \mathrm{FR}_{\mathrm{t}-1}, \mathrm{CR}_{-1}, \mathrm{CR}_{0}, \ldots, \mathrm{CR}_{\mathrm{t}-1}\right)$ with the given initial information $\Im_{0}=\left(\mathrm{FR}_{-1}\right.$, $\mathrm{CR}_{-1}$ )). The estimation procedure will be discussed in section 4.1. (We note that the complete information case corresponds to the case $b=0$ ).

\section{(iii) Controlling Variable}

From the actuary's point of view, $\mathrm{CR}_{\mathrm{t}}$ is a controlling variable to be determined by him/her. Without loss of generality, we assume that the decision at time $t$, determining $\mathrm{CR}_{\mathrm{t}}$, is influenced principally by the pace of funding up to $t$, $\left\{\mathrm{CR}_{\mathrm{i}}: \mathrm{i}=0,1, \mathrm{t}-1\right\}$, and the progress of the solvency level up to $t,\left\{\mathrm{FR}_{\mathrm{j}}: \mathrm{j}=0,1\right.$, $\mathrm{t}-1\}$. Thus, we are concerned with linear feedback (not feedforward) control, which implies that our funding plan is restricted by the causality principle i.e. present decisions, or control actions, should not depend on future controlled responses. We note also that the dynamic model (6) maintains linearity. In this respect, we assume that

$\mathrm{CR}_{\mathrm{t}}=\pi_{\mathrm{t}}\left(\Im_{\mathrm{t}}\right)$ for all $\mathrm{t} \in \mathrm{Z}$

so that control actions depend only on the currently available information and the functional form is linear with respect to $\mathfrak{I}_{t}$.

\section{(iv) Control Performance}

The scheme actuary will, in general, have their own solvency and funding targets for the realisation of their funding purpose such as maintaining (long-term) benefit security and contribution stability. Here, we denote the desired levels of $\mathrm{FR}_{\mathrm{t}}$ and $\mathrm{CR}_{\mathrm{t}}$ by $\mathrm{fr}_{\mathrm{t}}$ and $\mathrm{cr}_{\mathrm{t}}$, respectively. Unlike the approach 
of Haberman and Sung (1994), the following control performance index, $\mathrm{PI}_{\theta}$, is designed to give an undiscounted weighted penalty to the mismatches between $\mathrm{FR}_{t}$ and $\mathrm{fr}_{\mathrm{t}}$, and between $\mathrm{CR}_{t}$ and $\mathrm{cr}_{\mathrm{t}}$, caused by the control action $\mathrm{CR}_{\mathrm{t}}$. Because we are dealing with ratio measures rather than cash flows, we have used an undiscounted formulation. The weighting parameter $\theta(\in(0,1))$ is to be determined by the scheme actuary (balancing the interests of the scheme's sponsor and members).

$\mathrm{PI}_{\theta}=\mathrm{E}\left\{\sum_{\mathrm{t}=0}^{\mathrm{T}-1}\left[\theta\left(\mathrm{FR}_{\mathrm{t}}-\mathrm{fr}_{\mathrm{t}}\right)^{2}+(1-\theta)\left(\mathrm{CR}_{\mathrm{t}}-\mathrm{cr}_{\mathrm{t}}\right)^{2}\right]+\theta\left(\mathrm{FR}_{\mathrm{T}}-\mathrm{fr}_{\mathrm{T}}\right)^{2}\right\}$.

In the special case that $\mathrm{fr}_{\mathrm{t}}=\mathrm{E}\left(\mathrm{FR}_{\mathrm{t}}\right)$ and $c r_{\mathrm{t}}=\mathrm{E}\left(\mathrm{CR}_{\mathrm{t}}\right)$, then $\mathrm{PI}_{\theta}$ becomes

$\mathrm{PI}_{\theta}=\sum_{\mathrm{t}=0}^{\mathrm{T}-1}\left\{\left[\theta \cdot \operatorname{Var}\left(\mathrm{FR}_{\mathrm{t}}\right)+(1-\theta) \cdot \operatorname{Var}\left(\mathrm{CR}_{\mathrm{t}}\right)\right]+\theta \cdot \operatorname{Var}\left(\mathrm{FR}_{\mathrm{T}}\right)\right.$,

which gives the primary reason why a quadratic performance index is often considered in evaluating decision processes. This approach is considered further by Haberman et al (2000).

Hence, from the viewpoint of the realisation of our funding purpose, our performance criterion is, for a given $\theta$,

$$
\operatorname{Min}_{\left\{\mathrm{CR}_{\mathrm{t}} ; \mathrm{t}=0,1, \ldots, \mathrm{T}-1\right\}} \mathrm{PI}_{\boldsymbol{\theta}} \text {. }
$$

Finally, the control mechanism can be summarised by the diagram in Appendix A. The detailed procedure for establishing the dynamic pension funding plan will be given in the following sections.

\section{Control Optimisation Problem}

As specified in section 2, we consider the model given by (6), (7) and (8) with the quadratic optimisation criterion (10). This is a so-called stochastic LQP optimisation problem with incomplete state information.

Thus, our incomplete stochastic (pension funding) control problem over $[0, T]$ can be written in the form:

$\operatorname{Min}_{\left\{\mathrm{CR}_{t} ; t \geq 0,1, \ldots, \mathrm{T}-1\right\}} \mathrm{E}\left\{\sum_{\mathrm{t}=0}^{\mathrm{T}-1}\left\{\left[\theta\left(\mathrm{FR}_{\mathrm{t}}-\mathrm{fr}_{\mathrm{t}}\right)^{2}+(1-\theta)\left(\mathrm{CR}_{\mathrm{t}}-\mathrm{cr}_{\mathrm{t}}\right)^{2}\right]\right\}+\left[\theta\left(\mathrm{FR}_{\mathrm{T}}-\mathrm{fr}_{\mathrm{T}}\right)^{2}\right]\right\}$

subject to the linear stochastic dynamics model (6) with initially given $\Im_{0}=$ $\left(\mathrm{FR}_{-1}, \mathrm{CR}_{-1}\right)$, which is also applicable at $\mathrm{t}=-1 ; \mathrm{M}_{\mathrm{t}}=\mathrm{FR}_{\mathrm{t}-1}$; and $\mathrm{CR}_{\mathrm{t}}=\pi_{\mathrm{t}}\left(\mathfrak{I}_{\mathrm{t}}\right)$.

The procedure for solving the control problem (11) will be considered in the next section. 


\section{Solution of the Problem}

Apart from the fact that the current value of $\mathrm{FR}_{\mathrm{t}}$ in the controlled dynamic model (6) is no longer known to the actuary because $\mathrm{M}_{\mathrm{t}}=\mathrm{FR}_{\mathrm{t}-1}$, the control problem (11) is similar to the corresponding case of complete state information (as discussed by Haberman and Sung (1994)). Therefore, we need firstly to find an optimal state estimator to play the same role as the state variable representing the fund level in Haberman and Sung (1994). As explained in Appendix A, we can take advantage of the Separation Principle which is applicable to the control problem (11) because of its structure as an incomplete state stochastic LQP control problem. Then the procedure for solving the full problem can be separated into two steps: the first is to estimate optimally the currently unobservable state variable $F_{t}$ and the second is to solve the resulting control problem.

\subsection{Optimal Estimation of FRt}

Consider the situation at time $t \in Z$. Although $F R_{t}$ is not observable, its dynamics are governed by (6). Then, we define a new dynamic model, replacing (6), for a state variable which is generated recursively with certainty when the actuary makes his t-th decision (as in the complete state information case discussed by Haberman and Sung (1994)), and which also represents the current financial status in as small a dimension space as possible [see Whittle (1983, Ch 39)]. As a result of this argument, we propose that the conditional expectation $=\hat{F} R_{t}=E\left(F R_{t} \mid \Im_{t}\right)$ is the optimal solution of the problem of estimating the conceptual state $F_{t}$ for the following reasons (a) and (b): for each $\mathrm{t} \in \mathrm{Z}$,

(a) Assuming that $E\left(F R_{t}^{2}\right)<\infty$, then $\hat{F} R_{t}=E\left(F R_{t} \mid \Im_{t}\right)$ is the so-called minimum mean-squared error estimator of $F R_{t}$ given $\Im_{t}$, because setting $K_{t} \equiv$ $f\left(\Im_{t}\right)$ (i.e. an estimator of $\left.F R_{t}\right), \operatorname{Min}_{K_{t}} E\left[\left(F R_{t}-K_{t}\right)^{2}\right]=\operatorname{Min}_{K_{t}} E\left\{E\left[\left(F R_{t}-K_{t}\right)^{2}\right]\right.$ $\left\{\Im_{t}\right\}$ leads to our result. This implies that $\hat{F} R_{t}$ provides a "better" estimate for the inaccessible value of $F R_{t}$ from a given information vector $\Im_{t}$ than any other estimator. Furthermore, using the fact that

$\mathrm{FR}_{\mathrm{t}}=\exp \left(\varphi_{\mathrm{t}}\right) \cdot\left[\exp \left(-\mu-\sigma_{\mathrm{a}}^{2} / 2\right) \cdot \hat{\mathrm{F}} \mathrm{R}_{\mathrm{t}}+\mathrm{EBR}_{\mathrm{t}-1}-\mathrm{BR}_{\mathrm{t}-1}\right]$, then

$\operatorname{Pr}\left(\mathrm{FR}_{\mathrm{t}} \mid \Im_{\mathrm{t}}\right)=\operatorname{Pr}\left(\mathrm{FR}_{\mathrm{t}} \mid \hat{\mathrm{F}} \mathrm{R}_{\mathrm{t}}\right)$, which implies that the value of $\hat{\mathrm{F}} \mathrm{R}_{\mathrm{t}}$ provides complete information about the vector $\Im_{t}$.

(b) The sequence $\left\{\hat{F} R_{0}, \hat{F} R_{1}, \ldots, \hat{F} R_{T}\right\}$ is generated recursively by the following recursion:

$\hat{F R}_{t+1}=\exp \left(\mu+\sigma_{\mathrm{a}}^{2} / 2\right) \cdot\left[\exp \left(\varphi_{\mathrm{t}}-\mu-\sigma_{\mathrm{a}}^{2} / 2\right)\right.$.

$\left.\hat{F} R_{t}+C_{t}-E_{t} R_{t}+\exp \left(\varphi_{t}\right)\left(E B R_{t-1}-B_{t-1}\right)\right]$

with the initial condition $\hat{F R}_{0}=\exp \left(\mu+\sigma_{a}^{2} / 2\right) \cdot\left(\mathrm{FR}_{-1}-\mathrm{CR}_{-1}-\mathrm{EBR}_{-1}\right)$.

Hence, this new dynamic model is a stochastic difference equation of order one, which will sequentially generate $\hat{F} R_{t}$ with certainty and no time delay as 
time progresses. Furthermore, $\left\{\hat{F} R_{0}, \hat{F} R_{1} \ldots, \hat{F} R_{T}\right\}$ is a discrete-time, finite-state Markov process because $\operatorname{Pr}\left(\hat{\mathrm{FR}}_{t+1}, \hat{\mathrm{FR}}_{t+2}, \ldots, \hat{\mathrm{F} R} \mathrm{R}_{\mathrm{T}} \mid \Im_{t}\right)=\operatorname{Pr}\left(\hat{\mathrm{FR}} \mathrm{F}_{t+1}, \hat{\mathrm{F}} \mathrm{R}_{t+2}, \ldots\right.$, $\left.\hat{F} R_{t} \mid \hat{F} R_{t}\right)$.

As a result, $\hat{F} R_{t}$ summarises effectively all the information available to the actuary at the time of taking the control action $\mathrm{CR}_{\mathrm{t}}$ and is recursively calculable by means of the newly derived system equation (12), so that $\mathrm{FR}_{t}$ is a state variable of the controlled object specified by (12). It is then sufficient to determine $C_{t}$ as a linear function of $F R_{t}$, i.e. $C_{t}=\pi_{t}\left(\hat{F} R_{t}\right)$.

Therefore, the next step in the application of the Separation Principle is to seek the optimal solution to the incomplete control problem (11) assuming that complete state information is available and sequentially generated by way of redefining the controlled stochastic object by equation (12) instead of the original system equation (6). Hence, we can solve the problem (11) in a similar manner to the approach employed Haberman and Sung (1994) for the complete state information case. The optimisation procedure will be considered in the next section.

\subsection{Bellman Equation}

In order to solve the control problem (11), we apply the backward dynamic programming (BDP) approach (based on Bellman's principle of optimality: Bellman (1957)) developed in the field of optimal control theory. To produce the backward recursion in time $t \in Z$, we then define

$$
\begin{gathered}
\mathrm{V}(\hat{\mathrm{FR}} \mathrm{t}, \mathrm{t})=\operatorname{Min}_{\left\{\mathrm{CR}_{\mathrm{s}} ; \mathrm{s}=\mathrm{t}, \mathrm{t}+1, \ldots, \mathrm{T}-1\right\}} \mathrm{E}\left\{\sum_{\mathrm{s}=\mathrm{t}}^{\mathrm{T}-1}\left\{\left[\theta \cdot\left(\mathrm{FR}_{\mathrm{s}}-\mathrm{fr}_{\mathrm{s}}\right)^{2}+(1-\theta) \cdot\left(\mathrm{CR}_{\mathrm{s}}-\mathrm{cr}_{\mathrm{s}}\right)^{2}\right]\right\}+\right. \\
\left.\theta \cdot\left(\mathrm{FR}_{\mathrm{T}}-\mathrm{fr}_{\mathrm{T}}\right)^{2} \mid \widehat{F R}_{\mathrm{t}}\right\},
\end{gathered}
$$

which represents the minimal expected future mismatching penalty at time 0 , given the summarised information up to time t (i.e. the state variable $\hat{F} R_{t}$ ).

Then, we establish the following Bellman equation for sequential control optimisation: for each $t \in Z$,

$$
\begin{aligned}
& \mathrm{V}\left(\hat{\mathrm{FR}}_{\mathrm{t}}, \mathrm{t}\right) \\
& =\underset{\mathrm{CR}_{\mathrm{t}}}{\operatorname{Min} \mathrm{E}}\left\{\left[\theta \cdot\left(\mathrm{FR}_{\mathrm{t}}-\mathrm{fr}_{\mathrm{t}}\right)^{2}+(1-\theta) \cdot\left(\mathrm{CR}_{\mathrm{t}}-\mathrm{cr}_{\mathrm{t}}\right)^{2}\right]+\right. \\
& \mathrm{E}\left\{\left\{\sum_{\mathrm{s}=\mathrm{t}+1}^{\mathrm{T}-1}\left(\left[\theta \cdot\left(\mathrm{FR}_{\mathrm{s}}-\mathrm{fr}_{\mathrm{s}}\right)^{2}+(1-\theta) \cdot\left(\mathrm{CR}_{\mathrm{s}}-\mathrm{cr}_{s}\right)^{2}\right]\right)+\right.\right. \\
& \left.\left.\left.\theta \cdot\left(\mathrm{FR}_{\mathrm{T}}-\mathrm{fr}_{\mathrm{T}}\right)^{2}\right\} \mid \hat{\mathrm{F}} \mathrm{R}_{\mathrm{t}+1}\right\} \mid \hat{\mathrm{FR}} \mathrm{t}_{\mathrm{t}}\right\} \\
& =\underset{C R_{t}}{\operatorname{Min} E}\left\{\left\{\theta \cdot\left(\mathrm{FR}_{\mathrm{t}}-\mathrm{fr}_{\mathrm{t}}\right)^{2}+(1-\theta) \cdot\left(\mathrm{CR}_{\mathrm{t}}-\mathrm{cr}_{\mathrm{t}}\right)^{2}\right]+\mathrm{V}\left(\hat{\mathrm{F} R} \mathrm{R}_{\mathrm{t}+1}, \mathrm{t}+1\right) \mid \hat{\mathrm{FR}} \mathrm{R}_{\mathrm{t}}\right\}
\end{aligned}
$$


with the boundary condition $V\left(\hat{F} R_{T}, T\right)=E\left\{\theta \cdot\left(F_{T}-f r_{T}\right)^{2} \mid \hat{F} R_{T}\right\}$.

Here, $V\left(\hat{\mathrm{F}} \mathrm{R}_{\mathrm{T}}, \mathrm{T}\right)$ is computed as

$\mathrm{V}\left(\hat{\mathrm{F} R} \mathrm{R}_{\mathrm{T}}, \mathrm{T}\right)=\theta \cdot\left\{\exp \left(\sigma_{\mathrm{a}}^{2}\right) \cdot \hat{\mathrm{FR}}_{\mathrm{T}}^{2}-2 \cdot \mathrm{fr}_{\mathrm{T}} \cdot \hat{\mathrm{FR}}_{\mathrm{T}}+\exp \left(2 \mu+2 \sigma_{\mathrm{a}}^{2}\right) \cdot \mathrm{VBR}_{\mathrm{T}-1}+\mathrm{fr}_{\mathrm{T}}^{2}\right\}$.

\subsection{Control optimisation}

Utilising the fact that the control law at time $t$ is a linear function of the (currently observable) dynamic state $\hat{F}_{t}\left(\right.$ i.e. $C_{t}=\pi_{t}\left(\hat{F} R_{t}\right)$ ), we can demonstrate that the solution of the Bellman equation (13) is uniquely determined by the following quadratic form, as shown at the terminal time $\mathrm{T}$ (i.e. $\mathrm{V}(\hat{\mathrm{FR}} \mathrm{T}, \mathrm{T})$ ):

$V\left(\hat{F} R_{t}, t\right)=A_{1}(t) \cdot \hat{F} R_{t}^{2}+A_{2}(t) \cdot \hat{F} R_{t}+A_{3}(t)$

with the boundary conditions:

$A_{1}(T)=\theta \cdot \exp \left(\sigma_{a}^{2}\right)$,

$\mathrm{A}_{2}(\mathrm{~T})=-2 \cdot \theta \cdot \mathrm{fr}_{\mathrm{T}}$ and

$A_{3}(T)=\theta \cdot\left[\exp \left(2 \mu+2 \sigma_{a}^{2}\right) \cdot V B R_{T-1}+f r_{T}^{2}\right]$.

This result is demonstrated below, using a mathematical induction argument. As we know from the Bellman equation (13), the first step for solving (13) is to determine the conditional first and second moments of $F R_{t}$ and $\hat{F R}_{t+1}$ given $\hat{F} R_{t}$ which come from the following equations:

$\mathrm{FR}_{\mathrm{t}}=\exp \left(\varphi_{\mathrm{t}}\right) \cdot\left[\exp \left(-\mu-\sigma_{\mathrm{a}}^{2} / 2\right) \cdot \hat{\mathrm{FR}}_{\mathrm{t}}+\mathrm{EBR}_{\mathrm{t}-1}-\mathrm{BR}_{\mathrm{t}-1}\right]$ and

$\hat{F}_{t+1}=\exp \left(\mu+\sigma_{a}^{2} / 2\right)\left[\exp \left(\varphi_{t}-\mu-\sigma_{a}^{2} / 2\right) \hat{F R}_{t}+\right.$

$$
\left.\mathrm{CR}_{\mathrm{t}}-\mathrm{EBR}_{\mathrm{t}}+\exp \left(\varphi_{\mathrm{t}}\right)\left(\mathrm{EBR}_{\mathrm{t}-1}-\mathrm{BR}_{\mathrm{t}-1}\right)\right]
$$

And then, the conditional first and second moments are obtained in the form $\mathrm{E}\left\{\mathrm{FR}_{\mathrm{t}} \mid \hat{\mathrm{FR}} \mathrm{t}_{\mathrm{t}}\right\}=\mathrm{E}\left\{\mathrm{FR}_{\mathrm{t}} \mid \Im_{\mathrm{t}}\right\}=\hat{\mathrm{FR}} \mathrm{t}_{\mathrm{t}}$,

$E\left\{F_{t}^{2} \mid \hat{F R}_{t}\right\}=\exp \left(\sigma_{a}^{2}\right) \cdot \hat{F R}_{t}^{2}+\exp \left(2 \mu+2 \sigma_{a}^{2}\right) \cdot V_{B R}$,

$\mathrm{E}\left\{\hat{\mathrm{F}} \mathbf{R}_{\mathrm{t}+1} \mid \hat{\mathrm{F}} \mathbf{R}_{\mathrm{t}}\right\}=\exp \left(\mu+\sigma_{\mathrm{a}}^{2} / 2\right) \cdot\left[\hat{F}_{\mathrm{t}}+\mathrm{CR}_{\mathrm{t}}-\mathrm{EBR}_{\mathrm{t}}\right]$,

$E\left\{\hat{F} R_{t+1}^{2} \mid \hat{F} R_{t}\right\}=\exp \left(\mu+\sigma_{a}^{2}\right) \cdot\left[\exp \left(\sigma_{a}^{2}\right) \cdot \hat{F} R_{t}^{2}+2\left(C_{t}-E B R_{t}\right) \cdot \hat{F} R_{t}+\right.$

$$
\left.\left(\mathrm{CR}_{\mathrm{t}}-\mathrm{EBR}_{\mathrm{t}}\right)^{2}+\exp \left(2 \mu+2 \sigma_{\mathrm{a}}^{2}\right) \cdot \mathrm{VBR}_{\mathrm{t}-1}\right] \text {. }
$$

Using the above results, we can simply rewrite the Bellman equation (13) in the form: for each $t \in Z$, 
$\mathrm{V}\left(\hat{\mathrm{F}} \mathbf{R}_{\mathrm{t}}, \mathrm{t}\right)$

$=\underset{\mathrm{CR}_{t}}{\operatorname{Min}}\left\{\mathrm{X}_{1}(\mathrm{t}) \mathrm{CR}_{\mathrm{t}}^{2}+\mathrm{X}_{2}(\mathrm{t}) \mathrm{CR}_{\mathrm{t}}+\mathrm{X}_{3}(\mathrm{t})\right\}$ in which

$X_{1}(t)=(1-\theta)+\exp \left(2 \mu+\sigma_{a}^{2}\right) \cdot A_{1}(t+1)$,

$X_{2}(t)=-2 c r_{t} \cdot(1-\theta)+2\left[\exp \left(2 \mu+\sigma_{a}^{2}\right) \cdot A_{1}(t+1)\right] \cdot\left(\hat{F} R_{t}-E_{B R}\right)+\exp \left(\mu+\sigma_{a}^{2} / 2\right)$.

$\mathrm{A}_{2}(\mathrm{t}+1)$ and

$\mathrm{X}_{3}(\mathrm{t})=\theta \cdot\left[\exp \left(\sigma_{\mathrm{a}}^{2}\right) \cdot \hat{\mathrm{F}} \mathrm{R}_{\mathrm{t}}^{2}+\exp \left(2 \mu+\sigma_{\mathrm{a}}^{2}\right) \cdot \mathrm{VBR}_{\mathrm{t}-1}-2 \mathrm{fr}_{\mathrm{t}} \cdot \hat{\mathrm{FR}}_{\mathrm{t}}+\mathrm{fr}_{\mathrm{t}}^{2}\right]+(1-\theta) \cdot \mathrm{cr}_{\mathrm{t}}^{2}$

$+\exp \left(2 \mu+\sigma_{a}^{2}\right) \cdot A_{1}(t+1) \cdot\left[\exp \left(\sigma_{a}^{2}\right) \cdot \hat{F} R_{t}^{2}-2 E B R_{t} \cdot \hat{F R}_{t}+E B B R_{t}{ }^{2}+\exp \left(2 \mu+2 \sigma_{a}^{2}\right) \cdot\right.$

$\left.\operatorname{VBR}_{t-1}\right]+\exp \left(\mu+\sigma_{a}^{2} / 2\right) \cdot A_{2}(t+1) \cdot\left(\hat{F} R_{t}-E_{B R}\right)+A_{3}(t+1)$.

Hence, we can obtain the unique sequence of optimal control actions $\left\{\mathrm{CR}_{\mathrm{t}}^{*}\right.$; $t \in Z\}$ under the following condition for all $t \in Z$,

$X_{1}(t)>0$ (or equivalently, $\left.A_{1}(t+1)>-\frac{(1-\theta)}{\exp \left(2 \mu+\sigma_{a}^{2}\right)}\right)$

Differentiating the convex function in (16) with respect to $C R_{t}$, we then derive the optimal control action at time $t, \mathrm{CR}_{t}^{*}\left(=\pi_{t}^{*}\left(\hat{\mathrm{F} R} \mathrm{R}_{\mathrm{t}}\right)\right)$, which can be written as:

$C R_{t}^{*}=-\frac{D_{1}(t)}{D_{3}(t)} \cdot \hat{F} R_{t}+\frac{D_{2}(t)}{D_{3}(t)}$, in which

$D_{1}(t)=\exp \left(2 \mu+\sigma_{a}^{2}\right) \cdot A_{1}(t+1)$

$\mathrm{D}_{2}(\mathrm{t})=\mathrm{cr}_{\mathrm{t}} \cdot(1-\theta)+\exp \left(2 \mu+\sigma_{\mathrm{a}}^{2}\right) \cdot \mathrm{A}_{1}(\mathrm{t}+1) \cdot \mathrm{EBR}_{\mathrm{t}}-\exp \left(\mu+\sigma_{\mathrm{a}}^{2} / 2\right) \cdot \mathrm{A}_{2}(\mathrm{t}+1) / 2$

and

$D_{3}(t)=(1-\theta)+\exp \left(2 \mu+\sigma_{a}^{2}\right) \cdot A_{1}(t+1)$.

Thus, the contribution ratio postulated in (8) is optimally specified and then the optimal pension funding plan, $\left\{\pi_{t}^{*}():. t \in Z\right\}$, is clearly determined in a form which depends only on $A_{1}(t+1)$ and $A_{2}(t+1)$ (not on $A_{3}(t+1)$ ). So, we need only to specify the backward recursive equations below, obtained by substituting $\mathrm{CR}_{\mathrm{t}}^{*}$ into (16). For all $\mathrm{t} \in \mathrm{Z}$,

$A_{1}(t)=\left[\theta \cdot(1-\theta) \cdot \exp \left(\sigma_{a}^{2}\right)+\exp \left(2 \mu+2 \sigma_{a}^{2}\right) \cdot A_{1}(t+1)+\exp \left(4 \mu+2 \sigma_{a}^{2}\right)\right.$

$\left.\left(\exp \left(\sigma_{\mathrm{a}}^{2}\right)-1\right) \cdot \mathrm{A}_{1}(\mathrm{t}+1)^{2}\right] /\left[(1-\theta)+\exp \left(2 \mu+\sigma_{\mathrm{a}}^{2}\right) \cdot \mathrm{A}_{1}(\mathrm{t}+1)\right]$

with the boundary condition $A_{1}(T)=\theta \cdot \exp \left(\sigma_{a}^{2}\right)$,

and 


$$
\begin{aligned}
A_{2}(t)= & {\left[2 \cdot \exp \left(2 \mu+2 \sigma_{a}^{2}\right) \cdot\left((1-\theta) \cdot\left(\mathrm{cr}_{\mathrm{t}}-\mathrm{EBR}_{\mathrm{t}}\right)-\theta \cdot \mathrm{fr}_{\mathrm{t}}\right) \cdot \mathrm{A}_{1}(\mathrm{t}+1)+\exp \left(\mu+\sigma_{\mathrm{a}}^{2} / 2\right)\right.} \\
& \left.(1-\theta) \cdot \mathrm{A}_{2}(\mathrm{t}+1)-2 \cdot \theta \cdot(1-\theta) \cdot \mathrm{fr}_{\mathrm{t}}\right] /\left[(1-\theta)+\exp \left(2 \mu+\sigma_{\mathrm{a}}^{2}\right) \cdot \mathrm{A}_{1}(\mathrm{t}+1)\right] \\
& \text { with the boundary condition } \mathrm{A}_{2}(\mathrm{~T})=-2 \cdot \theta \cdot \mathrm{fr}_{\mathrm{T}} .
\end{aligned}
$$

These are soluble by back-tracking step by step, starting from the boundary conditions.

We note that the uniqueness condition (17) is redundant due to $\left\{A_{1}(t): t \in Z\right\}$ being a positive sequence. This is because $A_{1}(T)=\theta \cdot \exp \left(\sigma_{a}^{2}\right)>0$ and also if $A_{1}(t+1)>0$ then $A_{1}(t)>0$.

Therefore, the mathematical induction argument is complete, showing that the solution of the Bellman equation (13) is uniquely determined and is quadratic in form as postulated in (14).

The optimal funding ratio $\hat{F R}_{t+1}^{*}$ corresponding to $\mathrm{CR}_{t}^{*}$ is generated recursively with time $t$ in the form:

$$
\begin{aligned}
\hat{\mathrm{F} R} \mathrm{R}_{\mathrm{t}+1}^{*}= & \exp \left(\mu+\sigma_{\mathrm{a}}^{2} / 2\right) \cdot\left[\exp \left(\varphi_{\mathrm{t}}-\mu-\sigma_{\mathrm{a}}^{2} / 2\right) \cdot \hat{\mathrm{F}} \mathrm{R}_{\mathrm{t}}^{*}+\mathrm{CR}_{\mathrm{t}}^{*}-\mathrm{EBR}_{\mathrm{t}}+\right. \\
& \left.\exp \left(\varphi_{\mathrm{t}}\right)\left(\mathrm{EBR}_{\mathrm{t}-1}-\mathrm{BR}_{\mathrm{t}-1}\right)\right]
\end{aligned}
$$

with the initial condition $\hat{F R}_{0}=\exp \left(\mu+\sigma_{\mathrm{a}}^{2} / 2\right) \cdot\left(\mathrm{FR}_{-1}-\mathrm{CR}_{-1}-\mathrm{EBR}_{-1}\right)$.

The format of the solution is then similar to that obtained by Haberman and Sung (1994) for the complete state information case. This, similarity comes from the Separation Principle because, as noted earlier, this Principle makes it possible to reformulate an incomplete state control problem into its corresponding complete state control problem by way of replacing the conceptual state variable with its optimal state estimator.

\section{Comments On Optimal Funding Plan}

In this section, we give some further comments on the optimal contribution ratio defined in (18).

We rewrite the formula (18) in the form

$$
C R_{t}^{*}=\frac{D_{2}(t)-D_{1}(t)}{D_{3}(t)}-\frac{D_{1}(t)}{D_{3}(t)} \cdot\left(\hat{F} R_{t}-1\right)
$$

Thus, this transformed formula has a similar mathematical form to the spread funding formula specified in (B2) in Appendix B: that is, the fact that $\left\{A_{1}(t)\right.$ : $t \in Z\}$ is positive implies that $0<\frac{D_{1}(t)}{D_{3}(t)}<1$, so that $\frac{D_{1}(t)}{D_{3}(t)}$ can be thought of as corresponding to the spread parameter $k_{t}$ and $\frac{D_{2}(t)-D_{1}(t)}{D_{3}(t)}$ to the normal cost ratio $\mathrm{NR}_{\mathrm{t}}=\frac{\mathrm{NC}_{\mathrm{t}}}{\mathrm{AL}_{\mathrm{t}}}$. 
Further, we also rewrite (18), for the specific case $\mathrm{cr}_{\mathrm{t}}=\mathrm{NR}_{\mathrm{t}}$, as follows

$C R_{t}^{*}=N R_{t}-\xi(t) \cdot\left(\hat{F} R_{t}-1\right)-\zeta(t)$, in which

$\xi(t)=\frac{D_{1}(t)}{D_{3}(t)}$ and

$\zeta(t)=\exp (-\mu) \cdot \frac{D_{1}(t)}{D_{3}(t)}+\exp \left(\mu+\sigma_{a}^{2} / 2\right) \cdot \frac{A_{2}(t+1)}{2 \cdot D_{3}(t)}$.

Then, this formula has mathematically the same form as the spread funding formula (B2), except for the term $\zeta(\mathrm{t})$. Here, $\xi(\mathrm{t})$ can be thought of as the proportional state feedback controlling parameter (i.e. playing a similar role to $\mathbf{k}_{t}$ in (B2)), whereas $\zeta(\mathrm{t})$ can be regarded as an additive controlling parameter, playing the additional role of a cushion to improve the contribution stability and fund solvency at the same time.

These conclusions support the findings of Owadally and Haberman (1999, 2000) who demonstrate the efficiency of the spread method, based on proportional control, in achieving secure funding levels and stable contribution rates, albeit in the complete state information case.

Lastly, it would be worth noting that we can obtain a general solution $\pi_{t}^{*}($. for the stationary first-order (unconditional) autoregressive model AR(1) with $\delta_{t+1}=\eta+\gamma \cdot\left(\delta_{t}-\eta\right)+{ }^{a} \varepsilon_{t+1}$, only if $\gamma=0$, since expressions like $E\left\{A_{1}(t+1)\right.$. $\left(\exp \left(\delta_{t}\right) \mid \delta_{\mathrm{t}-1}\right\}$ and $\mathrm{E}\left\{\mathrm{A}_{2}(\mathrm{t}+1) \cdot\left(\exp \left(\delta_{\mathrm{t}}\right) \mid \delta_{\mathrm{t}-1}\right\}\right.$ are not integrable.

\section{Future Developments}

There are practical and academic areas in which the dynamic funding approach adapted in this paper could be extended and improved. Firstly, it would be worthwhile to extend the control period (T) to infinity. Secondly, even though benefit outgoes are assumed to be stochastic in this paper, stochastic modelling for each of the force of membership growth and salary inflation would be more realistic. Thirdly, a simple model is employed to represent the stochastic behaviour of the rate of investment return for the pension fund, because of the insolubility mentioned at the end of section 5. Possibilities for relaxing this assumption would be worthy of exploration.

New applications of control theory to problems in insurance and pensions are appearing with increasing frequency in the literature. In this paper, we would like to highlight the important role played by the Separation Principle, in allowing estimation and optimisation to be undertaken sequentially, so that a solution can be derived.

\section{ACKNOWLEDGEMENTS}

The authors would like to acknowledge the very helpful comments provided by the anonymous referee which have led to improvements in the presentation. 


\section{APPENDIX A}

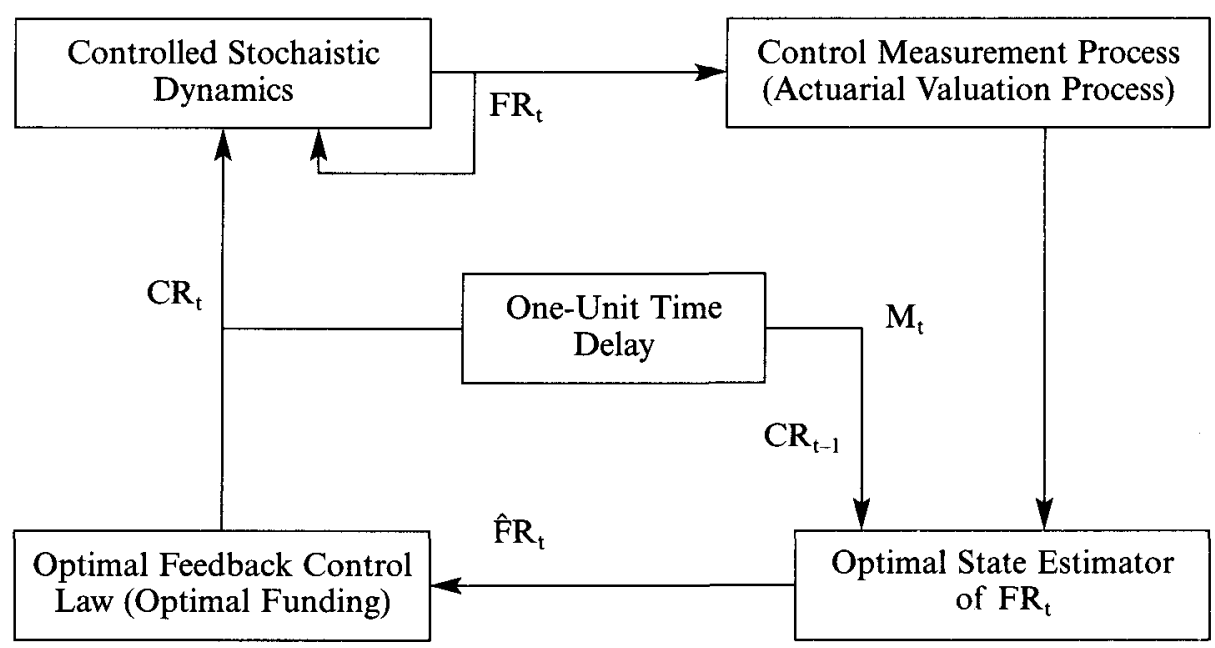

Optimal pension funding feedback control system for the incomplete state information case, starting with the initial information $\Im_{0}=\left(M_{0}, C_{-1}\right)$ given at time $\mathrm{t}=0 ; \mathrm{M}_{\mathrm{t}}=\mathrm{FR}_{\mathrm{t}-1}$ and $\hat{\mathrm{F}} \mathrm{R}_{\mathrm{t}}=\mathrm{E}\left(\mathrm{FR}_{\mathrm{t}} \mid \Im \mathrm{t}\right)$.

The "Optimal Feedback Control Law" represents a dynamic pension funding plan for the incomplete state information case, designed using control optimisation. The combination of the "Optimal Feedback Control Law" plus the "Optimal State Estimator of FR" (from section 4) is usually called the optimal feedback controller. This optimality structure is assured by the Separation Principle. This Principle is limited to stochastic LQP optimisation problems with incomplete state information and provides a connection between filtering theory and optimal stochastic LQP control problems as illustrated in the above figure. That is, the first part of the optimal controller is the estimator which, assuming no control action takes place, produces an optimal solution $\hat{F R}_{t}$ of the problem of estimating the conceptual state variable $F_{t}$ from the available information vector $\Im_{t}$. And the second part (of the optimal controller) is the control law which provides an optimal solution $\mathrm{CR}_{\mathrm{t}}$ of the control problem assuming the case of complete state information and using the state variable $\hat{F} R_{t}$. This property, which shows that these two parts of the optimal controller can be designed independently and separately as optimal solutions of an estimation and a control problem, has been called the Separation Principle and is widely applied to solve similar control problems - for more details, see, Bertsekas (1976) and Kwakernaak and Sivan (1972). 


\section{APPENDIX B}

As noted by Dufresne (1988) and Owadally and Haberman (1999), a commonly used method for adjusting the contribution in response to deviations in experience is to spread the unfunded liability at time $t, A_{t}-F_{t}$, over a spread period of $m$ years so that

$$
\mathrm{C}_{\mathrm{t}}=\mathrm{NC}_{\mathrm{t}}+\mathrm{k}\left(\mathrm{AL}_{\mathrm{t}}-\mathrm{F}_{\mathrm{t}}\right)
$$

where $\mathrm{k}=1 / \ddot{\mathrm{a}}_{\mathrm{m}}$, calculated at the valuation rate of interest $\mathrm{i}_{\mathrm{v}}$.

Dividing by $\mathrm{AL}_{\mathrm{t}}$ we obtain

$$
\mathrm{CR}_{\mathrm{t}}=\mathrm{NR}_{\mathrm{t}}+\mathrm{k}\left(1-\mathrm{FR}_{\mathrm{t}}\right)
$$

where $\mathrm{NR}_{\mathrm{t}}=\mathrm{NC}_{\mathrm{t}} / \mathrm{AL}_{\mathrm{t}}$. If we generalise the interpretation of $\mathrm{k}$ and replace it by $\mathrm{k}_{\mathrm{t}}\left(\right.$ for $\left.0<\mathrm{k}_{\mathrm{t}}<1\right)$ we obtain

$$
\mathrm{CR}_{\mathrm{t}}=\mathrm{NR}_{\mathrm{t}}-\mathrm{k}_{\mathrm{t}}\left(\mathrm{FR}_{\mathrm{t}}-1\right)
$$

which is used in the main text for comparison with the results emerging from the optimisation. 


\section{REFERENCES}

Bellman, R. (1957) "Dynamic Programming", Princeton University Press, Princeton.

BERTSEKAS, D.P. (1976) "Dynamic Programming and Stochastic Control”, Academic Press, New York.

Chang, S.C. (1999) "Optimal Pension Funding through Dynamic Simulations: the case of Taiwan Public Employees Retirement System". Insurance: Mathematics and Economics, 24, 187-199.

Dufresne, D. (1988) "Moments of Pension Fund Contributions and Fund Levels when Rates of Return are Random". Journal of the Institute of Actuaries, 115, 535-544.

Haberman, S. (1992) "Pension Funding with Time Delays - A Stochastic Approach" Insurance: Mathematics \& Economics 11, 179-189.

Haberman, S. (1993) "Pension Funding with Time Delays and Autoregressive Rates of Return". Insurance: Mathematics \& Economics 13, 45-56.

Haberman, S., Butt, Z. and Megaloudi, C. (2000) "Contribution and Solvency Risk in a Defined Benefit Pension Scheme". Insurance: Mathematics \& Economics, 27, 237-259.

Haberman, S. and SUnG J.H. (1994) "Dynamic Approaches to Pension Funding", Insurance: Mathematics and Economics, 15, 151-162.

KWAKERNAAK, H. and Sivan, R. (1972) "Linear Optimal Control Systems", Wiley-Interscience, New York.

KeyfiTZ, N. (1985). "Applied Mathematical Demography" (second edition). Springer, New York.

Owadally, M.I. and Haberman S. (1999) "Pension Fund Dynamics and Gains/Losses Due to Random Rates of Investment Return. North American Actuarial Journal, 3 (No 3), 105-117.

Owadally, M.I. and Haberman S. (2000) "Efficient Amortization of Actuarial Gains/Losses and Optimal Funding in Pension Plans". Actuarial Research Paper No 133, Department of Actuarial Science and Statistics, City University. Under review.

WhitTLE, P. (1983). "Optimization over Time: Dynamic Programming and Stochastic Control", Vol. II, John Wiley \& Sons, Chichester.

Zimbidis, A. and Haberman S. (1993) "Delay, Feedback and Variability of Pension Contributions and Fund Levels". Insurance: Mathematics and Economics 13, 271-285. 